written about the technique, and this volume, by Tibor Kremmer and László Boross, is the most recent. It has been translated from an original Hungarian version and contains three main chapters: "Theory", "Methods and Techniques", and "Applications". The first two chapters were written by Kremmer and the last by Boross. The authors have cited a large amount of the earlier work in the field but their description is not very lucid and contains numerous errors. Furthermore, a number of ambiguities have been introduced in the translation. The chapter on methods and techniques relies heavily on literature produced by the manufacturers of gels and chromatographic equipment; manufacturers' handbooks do, however, usually present the material in a clearer fashion.

The value of the book could have been that of a reference volume on the applications of gel chromatography in various fields; unfortunately, however, it is not up to date. The last reference cited is from 1976 and of the references only one out of six is from the five-year period 1972-76.

Given the lack of clarity and the dated section of references, this book is not an important addition to the literature on gel chromatography.

Torvard C. Laurent is Professor of Medical and Physiological Chemistry at the University of Uppsala, Sweden.

\section{Authority and politics on iron metabolism}

\section{William H. Crosby}

Iron Metabolism in Man. By T. H. Bothwell, R. W. Charlton, J. D. Cook and C. A. Finch. Pp.576. (Blackwell Scientific: Oxford, 1980.) $£ 33.50$.

THIS superb review and analysis is the product of four scientists, two South African, two American, whose long careers have been engrossed with iron nutrition and iron metabolism. It is a comfortably written book, authoritative and completely documented (more than 2,600 references) up to 1978 . It is a book that I shall use and treasure for the rest of my life.

The organization of the material departs from the ordinary in that a 240-page section on nutritional and clinical aspects comes first, followed by discussions of the basic physiology of iron metabolism. A third section (100 pages) describes in detail the laboratory methods that are used to study iron metabolism. Think of some aspect of iron in man and - except for 'spleen' - you'll find it listed in the index and discussed in the text in satisfactory detail.

All this is not to imply that there's no worm in the bud. During the past 20 years, the authors have been activists in the politics of nutrition, committed to universal fortification of foods with iron. Such programmes are intended to prevent mild iron deficiency. (It has yet to be demonstrated that fortification improves mildly iron-deficient people or injures those with undiagnosed iron-storage diseases, such as haemochromatosis.) The book is marked by a bias that favours fortification even at the expense of objectivity. Mild iron deficiency is treated with a concern worthy of a dread disease while the potentially lethal haemochromatosis is brushed across because it is rare, as though the improvement of a laboratory result in many could offset deadly damage done to only a few.

However rare haemochromatosis is, it would seem to be not rare enough. In a discussion of the evidence that haemochromatosis may develop only in homozygotes comes this observation: "Sheinberg has estimated the incidence of homozygous births as not more than 1 in 10,000 and heterozygous 1 in 50; the latter figure in particular seems at this time to be much too high". That the latter figure derives from the other is a matter of genetics and arithmetic, not opinion.

At one place in the book, the authors compute that a woman with normal iron stores would, during a normal pregnancy, have a requirement for an additional $740 \mathrm{mg}$ of iron. In another place, it is recommended that such women should receive $30 \mathrm{mg}$ per day of "supplemental

iron". In yet a third place, we find this polemic: "The presence of medicinal iron in the homes of pregnant women is responsible for the deaths of small children from acute iron poisoning, and nutritional deficiency must be held responsible for this too'".

Nutritional anaemia, in this setting, refers to the iron deficiency that results from copious menstrual blood loss.

There are other statements as unfortunate as these. Yet, in balance, the book is the best of its class; that it is also a vehicle for propaganda is sad.

William H. Crosby is at the Walter Reed Army Institute of Research, Washington DC.

\section{Periglacial processes six years on}

\section{R. J. E. Brown}

Geocryology: A Survey of Periglacial Processes and Environments. By A. L. Washburn. Pp.416. (Edward Arnold: London/Halsted Press: New York, 1979.) $£ 27.50, \$ 64.95$.

INCREASING recognition of the importance of resource developments in the cold areas of the Earth has focused continuing and growing concern on environmental conditions and physical processes in these regions. In 1973, A. L. Washburn published Periglacial Processes and Environments (Edward Arnold: London), which brought together the knowledge and ideas on this topic to that time. The present book is a revised and updated edition of that volume.

The author is one of the world's foremost authorities on processes taking place in cold regions, with more than 30 years' experience of the subject. He states that his book " . . is intended as a rather comprehensive overview of periglacial processes and their effects, present and past .... The book is neither a formal text nor a reference manual but something of both and a guide to the enormous literature. Geocryology is included in the title to emphasize the pervasive influence of ice and its phase changes in these processes. . . The term is in fact used in the restricted sense as applying to frozen ground (seasonally frozen ground as well as permafrost) but not to glaciers."

The 1973 edition was an impressive and most useful text; this volume is equally so, being monumental in its coverage of the field. No one involved in periglacial investigations can afford to be without it. The format of the new book with hard cover, $71 / 2^{\prime \prime} \times 10^{\prime \prime}$ page size and a full page of text in two columns is an improvement on the earlier work with its horizontal $8^{\prime \prime} \times$ $10^{\prime \prime}$ page size, smaller amount of text per page and single columns. The tremendous volume of literature that has appeared since 1973 and the author's thorough treatment of it are demonstrated by a comparison of the two editions. The 1973 edition has 262 pages, the 1979 publication 320 pages. However, the total text of the latter is nearly twice that of the former. The larger print of the earlier work is slightly easier to read but the smaller typeface used in the new work is no drawback. One of the most impressive aspects, and certainly an indication of the phenomenal increase of literature over six years, is the current bibliography. From about 1,000 references in 1973, the list has grown to about 2,700 . This is reflected in the text by the presence of one or more citations on virtually every line. I experienced some difficulty at first in 